Área Abierta. Revista de comunicación

audiovisual y publicitaria

ISSN: 2530-7592 / ISSNe: 1578-8393

\title{
Ajji (Abuelita): relato simbólico y escena primaria en la narrativa fílmica india de violación y venganza
}

Jaime López Díez ${ }^{1}$

Recibido: 7 de diciembre de 2019 / Aceptado: 11 de junio de 2020

Resumen. El presente estudio analiza la película india del género de violación y venganza Ajji (Devashish Makhija, 2017) y su relación con el inconsciente. Sus objetivos son identificar estructuras del inconsciente en el relato de Ajji para constatar si se trata de un relato simbólico desde la teoría del relato y la hipótesis de escena primaria de tipo "figura agresora materna" propuestas por González Requena. Con tal fin hemos empleado una metodología mixta cualitativo-cuantitativa, con un análisis de contenido de Ajji; un análisis de contenido de cuatro películas del mismo género estrenadas en India el mismo año; y una entrevista al director de la película, así como la revisión de otras entrevistas al mismo. Los resultados obtenidos confirman que Ajji no constituye un relato simbólico y manifiesta una escena primaria del tipo "figura agresora materna".

Palabras clave: Narrativa; Inconsciente; Escena primaria; Freud; Cine indio; Cine de violación y venganza

\section{[en] Ajji (Granny): Symbolic Stories and Primal Scene in Rape and Revenge Indian Film Narrative}

\begin{abstract}
This study analyzes the Indian rape and revenge film Ajji (Devashish Makhija, 2017), and its relationship with the unconscious mind. Its objectives are to identify the unconscious story axes to know if it may be categorized as a symbolic story, from the perspective of the theory of the story, and the hypothesis of a "mother figure aggressor" type of primal scene, as formulated by González Requena. To this end we have used a mixed qualitative-quantitative approach, combining content analysis of the film, as well as of four other films of the same genre released in India on the same year as Ajji, and an interview with the director of the film as well as a revision of other interviews with him. The results of the present study confirm that Ajji cannot be considered a symbolic story, and it shows a "mother figure aggressor" type of primal scene.
\end{abstract}

Keywords: Narrative; Unconscious Mind; Primal Scene; Freud; Indian Cinema; Rape and Revenge Films

Sumario. 1. Introducción. 2. Objetivos. 3. Metodología. 4. Análisis de contenido de Ajji. 5. Discusión. 6. Limitaciones. 7. Conclusiones. 8. Bibliografía.

Cómo citar. López Díez, Jaime (2020). Ajji (Abuelita): relato simbólico y escena primaria en la narrativa fílmica india de violación y venganza. Área Abierta. Revista de comunicación audiovisual y publicitaria 20 (2), 227-249, http://dx.doi.org/10.5209/arab.70084 


\section{Introducción}

El presente estudio analiza la película de temática de violación y venganza $A j j i$ (Ajji, Devashish Makhija, 2017) -cuyo título original en hindi puede traducirse como "abuelita" o "yaya"-y su relación con el inconsciente. En este sentido, partimos de la estrecha relación entre las obras fílmicas y productos del inconsciente como los sueños, las fantasías y las ensoñaciones diurnas, tal y como varios autores han destacado -Bulkeley, 2003; Cook, 2011; Marcus, 2008; Mulvey, 1989; Wilson, 2018-, así como varios directores de cine: Orson Welles -Bogdanovich, 1998: 280-; David Lynch -The West End Magazine|4101-TV, 2015-; o Ingmar Bergman - Tate, 1987-.

Algunos autores sostienen que la teoría del inconsciente de Freud, a pesar de sus limitaciones, "incluso hoy, es más específica y detallada que cualquier otra que pueda encontrarse en las psicología cognitiva o social contemporánea" (Bargh y Morsella, 2008: 73). Según Freud, un sueño es una manifestación del inconsciente -como las fantasías y las ensoñaciones diurnas (Freud, 1908/1976) - y su contenido, "la realización (disfrazada) de un deseo reprimido" (1900/1966: 227).

Si aceptamos la estrecha relación entre los sueños y las películas, estas pueden ser analizadas como los primeros. En especial, aquellos tipos de cine menos dependientes del mercado como el cine de autor, en el que el director trata de expresar su propia personalidad y estilo (Bordwell, Thompson y Smith, 2016), y el cine independiente, al margen de las grandes productoras (Levy, 1999). Ajji es un ejemplo de estos tipos de producciones (Bhattacharya, 2019).

\subsection{La teoría del relato de Jesús González Requena}

González Requena define relato como "la narración del trayecto del deseo de un Sujeto" (2006: 523). Su teoría del relato toma como referencia el análisis del cuento maravilloso de Vladimir Propp, del que extrae dos ejes narrativos, el eje de la Carencia -o del Deseo- y el eje de la Donación -o de la Ley-. Y distingue entre dos modelos de relato: el estructurado únicamente en el eje de la Carencia:

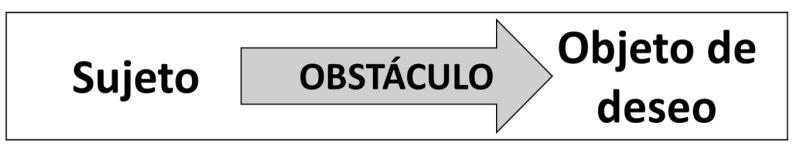

Cuadro 1. El relato no simbólico.

[Fuente: elaboración propia, basado en González Requena, 2006]

Y aquel en el que están presentes los dos ejes: el eje de la Carencia y el eje de la Donación -o de la Ley-: 


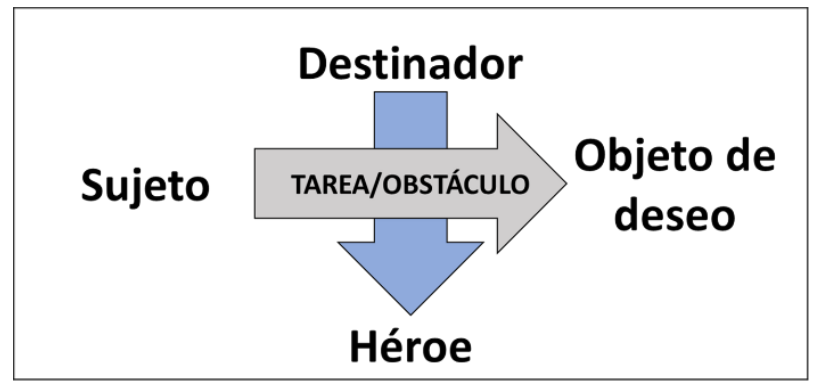

Cuadro 2. El relato simbólico.

[Fuente: elaboración propia, basado en González Requena, 2006]

En el eje de la Donación aparece la figura narrativa del Destinador, que encarna la Ley, y cumple cuatro funciones: "formular la prohibición, enunciar el mandato - de la Tarea-, otorgar el objeto mágico y sancionar la victoria" (González Requena, 2006: 526). Estas funciones resultan de agrupar las dos manifestaciones del Destinador del esquema actancial de Greimas -el Destinador-manipulador y el Destinador-juez (Greimas y Courtés, 1982) -; y, principalmente, cuatro de las funciones proppianas -II, IX, XIV y XXVII-, y varias de sus esferas de acción: Mandatario, Donante, y el Padre de la princesa (González Requena, 2006; Propp, 1971). Observa, además, este autor, que la relación del modelo de Propp para los cuentos maravillosos no solo puede asociarse a la trama edípica freudiana, sino con el momento "positivo" de la función paterna, asociada a la figura narrativa del Destinador (González Requena, 2006: 542).

En los relatos estructurados con ambos dos ejes, González Requena (2006) distingue un modelo que denomina relato simbólico, porque conduce al espectador a la experiencia del símbolo - "formación simbólica correcta", opuesta a la del síntoma, que sería la "formación simbólica deficitaria"- (2006: 541). Los cuentos de hadas, los mitos -entendidos como relatos cuya función es "introducir en lo real una [...] cadena de sentido" (2006: 563)-, la tragedia griega clásica y el modo clásico del cine de Hollywood son ejemplos de relatos simbólicos. Los modos manierista y postclásico del cine de Hollywood son ejemplos de relatos no simbólicos (2006: 582).

La importancia de distinguir entre ambos es que los relatos simbólicos vehiculan el deseo de los miembros de la sociedad que los reciben hacia un horizonte de madurez psíquica y sexual, entendidas ambas desde una perspectiva freudiana (2006: 541-542). En este sentido, señala cómo la actual crisis de relatos simbólicos en Occidente podría estar asociada a la crisis de la figura paterna y a la crisis de natalidad actual (2006: 542).

\subsection{La escena primaria}

Según la teoría del inconsciente de Freud. las fantasías, que González Requena denomina "escenas fantasmáticas" (2011), son puestas en escena de un deseo prohibido, "guiones de escenas organizadas capaces de ser dramatizadas, habitualmente de forma visual" (Laplanche y Pontalis, 1988: 318). Constan de, al menos, dos protagonistas: el sujeto y "cierto fantasma" (González Requena, 2011: 341). Su importancia podría ser tal que, según González Requena, "en toda gran obra de arte late una 
escena fantasmática" y "la obra de un gran artista [...] es un proceso de aproximación y depuración progresiva que conduce a dar forma $-\mathrm{y}$, cuando ello es posible a trascender-su escena fantasmática" (2011: 17).

Pero no todas las fantasías tienen la misma relevancia para el individuo. Freud destaca de entre ellas ${ }^{2}$ la escena primaria, es decir, la fantasía originaria del niño sobre el coito de los padres (González Requena, 2011). Pueden distinguirse dos tipos de escenas primarias. En ambos, el acto sexual es fantaseado como la agresión de un progenitor a otro. En la escena primaria descrita por Freud, el agresor es la figura paterna. Dado que cuando el niño elabora esta fantasía se encuentra en la fase de identificación primaria -también llamada de narcisismo primario- con la figura materna, la escena primaria es expresada como "mi papá me pega". En ella, la figura paterna agrede y "castra" a la figura materna primordial, desposeyéndola de su omnipotencia, lo que permite al yo del sujeto desagregarse de ella, abandonar la fase de identificación primaria y poder acceder a la individualidad. Por su parte, González Requena sugiere un segundo tipo en el que el agresor es la figura materna. Podría expresarse como "mi madre devora a mi padre" o "mi mamá me pega". Al no desposeer la figura paterna a la materna del falo que la revestía de omnipotencia, el yo del individuo no podría desagregarse de la imago-materna y quedaría apresado en la identificación primaria, lo que podría dificultar su proceso de maduración psíquica y genital.

Este segundo tipo de escena primaria, señala González Requena “quizás haya pasado a convertirse en un dato masivo de nuestra sociedad occidental contemporánea -y de su cada vez más intenso y desasosegante malestar" (2011: 356).

\subsection{El cine de violación y venganza}

La temática de violación y venganza puede definirse como "aquella en la que una violación esencial para la historia es castigada con un acto de venganza, ya sea por las propias víctimas o por otro agente: un abogado, un policía o, más frecuentemente, un ser querido o un familiar de la víctima" (Heller-Nicholas, 2011: 3). La estructura narrativa canónica incluye la culpabilización de la víctima, el traslado del juicio sobre la moralidad de la violación a la mujer, el fracaso de la ley para las víctimas y la subsiguiente venganza (Jha, 2017).

Varios autores han tratado de esclarecer qué tipo de placer escópico subyace en este género -Clover, 1993; Ebert; 1989; Heller-Nicholas, 2011, Lehman, 1993; Read, 2000; Williams, 1989-. Algunos señalan un cierto disfrute en el espectador masculino por ver las escenas de violación, y un cierto disfrute en el espectador femenino por ver las escenas de venganza Ebert, 1989); otros -Clover, 1993; Lehman, 1993- sugieren que implican un placer escópico más complejo. Así, Lehman señala que, en este tipo de películas, "casi siempre hechas por hombres y para hombres" (1993: 107), la violación suele realizarse por un grupo de amigos, lo que remite a lazos homoeróticos (1993: 107), al tiempo que motiva una repetición de escenas de venganza, en las que, generalmente, el vengador es una mujer. La violencia de esta es creciente y culmina en un clímax en el que el agresor principal es asesinado, estructura que remite al acto sexual (Lehman, 1993: 107).

Las otras tres fantasías originarias son la de la vida intrauterina, la de castración y la de seducción ( Laplanche y Pontalis, 1988). 
Por otra parte, Lehman observa que, en un género en el que los hombres son colocados en un lugar pasivo, tradicionalmente reservado para las mujeres, y en el que el castigo es extremadamente espectacularizado, subyace un posible placer masoquista para el espectador masculino (1993: 113). Finalmente, señala que "el ataque brutal al cuerpo masculino, en general, y a sus genitales, en particular, por parte de una bella mujer" disfraza un deseo homosexual reprimido (1993: 116).

\subsection{El cine de violación y venganza en India: diferencias con Bollywood}

El cine de violación y venganza indio y, en especial, el de Bollywood, posee ciertos rasgos diferenciadores respecto al hollywoodiense: en primer lugar, sus picos de producción suelen estar relacionados con movilizaciones sociales multitudinarias por casos de violación (Gopalan, 1997; Jha, 2017; Virdi,1999); y en segundo, la mitología hindú está presente en muchas obras del género (Heller-Nicholas, 2011; Karki, 2018; Virdi, 2003).

Dos son las principales olas de cine de violación y venganza en India, ligadas a sendos casos de violación (Jha, 2017): el "caso Mathura", referente a la violación de una adolescente en 1972 por dos policías que, en 1979, fueron absueltos, lo que dio lugar a la primera película india de esta temática, Insaaf ka Taraazu (B.R. Chopra, 1980) (La balanza de la justicia ${ }^{3}$ ) (Gopalan, 1997, Jha, 2017); y el "caso Nirbhaya" ("sin miedo", en hindi), alusivo a la violación y asesinato de la estudiante de 23 años Jyoti Singh Pandey, y la agresión a su pareja, en diciembre de 2012, suceso que dio lugar a la mayor movilización popular en la historia de la India contra la violencia sexual (Jha, 2017). A esta segunda ola pertenecen obras como Mardaani (Pradeep Sarkar, 2014) -Masculinidad-, Lakshmi (Nagesh Kukunoor, 2014) o 7 diosas (Angry Indian Goddesses, Pan Nalin, 2015). En 2017 se produce una eclosión del género con el estreno de varias obras representantivas del mismo entre las que se encuentra Ajji.

Respecto a la mitología hindú, es frecuente que en la venganza se apele a deidades femeninas violentas. Heller-Nicholas señala cómo Kali, Durga o Draupadi, personaje femenino del texto sagrado Mahabharata que ejecuta una venganza, son evocadas explícitamente (2011: 132). Kali, por ejemplo, la más iracunda de las diosas hindúes, es invocada varias veces en la película 7 diosas, en la que un personaje dice: "creo que todas llevamos una Kali dentro de nosotras". Sobre la relación entre la narrativa y la maquinaria visual en este género, Gopalan señala que "gira en torno al problema del equilibrio entre la violación y la venganza” (1997: 51), y pone como ejemplo de asimetría entre ambas las películas Pratighat (Chandrashekhar Narvekar, 1987) - Venganza-, en la que una violación es vengada asesinando al violador, y Zakmi Aurat (Avtar Bhogal, 1988) -Mujer herida-, en la que el violador es emasculado por un grupo de mujeres. Gopalan observa que en este desequilibrio "resuena una utopía feminista en la que, al menos momentáneamente, la fácil ecuación económica entre pene y falo resuelve las diferencias entre género y poder que, constantemente, se complican por, y están sujetas a, la diferencia simbólica entre el pene y el falo" (Gopalan, 1997: 51).

Cuando las películas citadas no tienen título para el mercado hispanófono, hemos optado por incluir una posible traducción del título original. 


\section{Objetivos}

El objetivo principal de este estudio es indagar en la estructura del relato en el cine independiente en hindi de temática de violación y venganza desde el punto de vista del inconsciente. Para ello hemos escogido una obra significativa de este tipo de cine, $A j j i$, que ha obtenido varios premios internacionales y nominaciones en distintas categorías, además de críticas positivas en la prensa especializada (Yoodle Films, 2017). Un segundo objetivo general ha sido estudiar la simetría o asimetría de la agresión y la venganza en este género, rasgo relevante para comprender el mismo según Gopalan (1997).

Los objetivos específicos han sido, en primer lugar, categorizar la película Ajji como relato simbólico o no simbólico; en segundo lugar, identificar el tipo de escena primaria presente en la película; en tercer lugar, estudiar películas indias del género coetáneas a $A j j i$; y, por último, conocer la motivación del director de la película en su proceso creativo. Asimismo, teniendo en cuenta que este género surgió en los inicios del modo de relato no simbólico del cine de Hollywood, hemos formulado la siguiente hipótesis: la película Ajji no presenta rasgos significativos y/o definitivos que puedan identificarla como un relato simbólico.

\section{Metodología}

Hemos planteado una metodología triangular o multimétodo (Denzin, 1970) de tipo cualitativa, pero con resultados cuantitativos derivados de los análisis cualitativos. En este sentido, se trata de una metodología mixta cualitativa-cuantitativa (Teddlie y Tashakkori, 2009). Los tres métodos de análisis del objeto de estudio han sido: primero, el análisis de contenido de la película $A j j i$; segundo, el análisis de películas indias de violación y venganza coetáneas de $A j j i$; y tercero, la revisión de entrevistas al director y entrevista personal al mismo.

El análisis de contenido de Ajji ha sido de tipo "fragmentario" (Santos Zunzunegui, 1994: 94), tratando de aproximarnos en lo posible al modelo de análisis textual propuesto por González Requena (Casanova, 2011; González Requena, 2007), de inspiración en Barthes (1977) y Freud (1900), y consistente en "deletrear" el texto filmico, su contenido y aspectos formales, evitando interpretaciones a priorísticas y teniendo en cuenta las emociones del investigador (González Requena, 2007).

Para realizar el análisis, en primer lugar, hemos segmentado la obra según sus secuencias (Bordwell, 2017; McKee, 2009). Luego, para categorizar la película como relato simbólico o no simbólico, se ha tratado de identificar el eje de la Donación, caracterizado por la figura narrativa del Destinador. Para ello, hemos estudiado dos variables, basándonos, en parte, en la tipología propuesta por Burguera (2015), a partir de González Requena (2006). Por un lado, hemos distinguido entre un Destinador explícito, cuando un personaje del relato cumple las cuatro funciones de esta figura narrativa; y un Destinador implícito, cuando en la puesta en escena o de forma implícita en la enunciación del relato se activan dichas funciones; un ejemplo sería la presencia de simbología religiosa. En segundo lugar, hemos estudiado si, aun habiendo un Destinador evidente, este es simbólico, cuando encarna la ley y una figura paterna simbólica, y conduce al espectador a la experiencia del símbolo, y no del síntoma; o no simbólico, cuando conduce al espectador a 
la experiencia del síntoma. Asimismo, se han buscado rasgos identificativos de la escena primaria.

En cuanto al análisis de películas indias de violación y venganza coetáneas de Ajji, el criterio de selección de las películas para este tipo de análisis ha sido el siguiente: en primer lugar, que su temática fuera de violación y venganza; en segundo lugar, que hubieran sido estrenadas en 2017; y, por último, que su idioma original fuera el hindi. Hemos extraído la muestra del listado de la base de datos Bollywoodmdb.com, una de las páginas líderes sobre cine de Bollywood (Bollywoodmdb, 2020). Cinco películas cumplen los criterios establecidos: Kaabil (Sanjay Gupta, 2017) -Capaz, estrenada en enero-; Maatr (Ashter Syed, 2017) -Madre, estrenada en abril-; Mom (Ravi Udyawar, 2017) -Mamá, estrenada en julio-; Bhoomi (Omung Kumar, 2017) -Tierra, estrenada en septiembre-; y Ajji (Ajji, Devashish Makhija, 2017) - estrenada en noviembre ${ }^{4}$.

Las categorías analizadas han sido las siguientes: violencia sobre las víctimas; violencia sobre los agresores; sexo de las víctimas; sexo de los agresores; edad de las víctimas; edad de los agresores; edad de los vengadores; relación de parentesco entre vengador y víctima; tipo de Destinador.

Como tercer elemento metodológico, hemos realizado una entrevista personal al director de Ajji, Devashish Makhija, además revisar otras entrevistas accesibles via online. La entrevista personal fue realizada por correo electrónico (Makhija, 2019, comunicación personal, 17 de mayo) y le formulamos tres preguntas: 1) En la película $A j j i, ~ ¿ c o n$ qué personaje se identifica más?; 2) ¿Por qué el personaje de Ajji castra y mata al personaje de Dhavle hijo con unas tijeras y no con un cuchillo, dado que es con este último instrumento con el que ha estado aprendiendo a cortar carne?; y 3) ¿Qué deidad hindú preside el altar presente en la casa de Dhavle hijo?

\section{Análisis de contenido de $A j j i$}

La acción de Ajji transcurre en un gran barrio de chabolas de Bombay. La hemos segmentado del siguiente modo:

C. Títulos de crédito iniciales.

1. La búsqueda de Mandá. Ajji, acompañada de Leela, una prostituta, busca a su nieta, Mandá, quien, ya de noche, no ha regresado a casa; Ajji y Leela encuentran a Mandá, malherida, en un vertedero de basura.

2. El interrogatorio. El inspector Dastur interroga a Ajji, Leela y los padres de Mandá, Milind y Vibha; Mandá sugiere que su agresor ha sido Dhavle, hijo de un político; El inspector intimida a la familia para que no lo denuncien.

3. La guarida de Dhavle. Mandá identifica a Dhavle en una foto y dice a Ajji el lugar donde fue violada; Ajji va a la guarida de Dhavle e imagina la violación.

4. La carnicería de Sharafat. Ajji convence a Sharafat, carnicero musulmán, para que le enseñe a cortar carne.

Ninguna ha sido estrenada oficialmente en España, según Internet Movie Data Base (Internet Movie Data Base, 2020) y, según la misma web, solo Ajji tiene un título específico para el mercado en español, que es Ajji. 
5. La parodia del acto sexual. Dhavle, acompañado de su cómplice, Umya, despieza un maniquí y simula su violación, siendo espiados por Ajji.

6. La casa de Dhavle. La mujer de Dhavle lo bendice ritualmente; El inspector Dastur es humillado por Dhavle y Umya cuando trata de interrogar al primero; Dhavle padre niega a Dastur el pago de un médico que ha examinado a Mandá.

7. Ajji prosigue su adiestramiento en el manejo del cuchillo. Ajji corta los testículos de una cabra y se los da de comer a unos perros; Milind, padre de Mandá, se corta gravemente la mano en la fábrica; Ajji mata a una gallina cortándole el cuello.

8. Dhavle padre censura a su hijo. Ajji, armada con un cuchillo, espía a Dhavle y Umya en su guarida; Dhavle padre llega y abofetea a su hijo; Dolly, prostituta amiga de Leela, ha sido agredida y violada por Dhavle.

9. Ajji se prepara para castrar y matar a Dhavle. Un afilador afila el arma de Ajji; Leela maquilla a Ajji como prostituta.

10. Ajji cumple su venganza. Ajji sigue a Dhavle; Ajji castra y mata a Dhavle; Ajji da de comer los testículos de Dhavle a un perro.

11. En casa, de nuevo. Ajji mira a Mandá durmiendo en la cama de sus padres; Ajji descansa, apoyada en la pared, con una expresión de cansancio y resignación.

12. Títulos de crédito finales.

Para el análisis de la película, hemos considerado protagonista de la misma a Ajji. La obra presenta una estructura próxima a la canónica de este género (Jha, 2017): se produce una violación; la ley, representada por el policía Dastur, fracasa en hacer justicia; y una persona próxima a la víctima, la abuela, ejecuta la venganza. A diferencia de los ejemplos más representativos del género, el espectador no presencia la escena de violación ${ }^{5}$, pues esta ya ha sido consumada cuando comienza el relato.

\subsection{El Destinador}

En Ajji, ningún personaje encarna explícitamente las cuatro funciones del Destinador; ninguno enuncia una prohibición a Ajji ni le ordena la tarea de hacer justicia a la violación, ni sanciona el éxito de su venganza. Algunos personajes, por separado, ejercen algunas funciones del Destinador. Así, el carnicero Sharafat adiestra a Ajji en el manejo de un objeto con el que ejecutar la venganza, un cuchillo. Aunque resulta llamativo que, finalmente, la protagonista utilice unas tijeras para consumarla, con lo que no se vale de "objeto mágico" entregado por Sharafat.

La ley es representada en el relato por el inspector de policía Dastur. Pero este es incapaz de hacer que se cumpla porque trabaja para el padre del agresor, un político corrupto, minimizando las consecuencias de las tropelías de su hijo. Otro posible Destinador, en este caso implícito, es Shiva -ver imagen uno-, al que hay dedicado un altar en casa de Dhavle, donde vemos, también, una inscripción del mantra sagrado $\mathrm{Om}$.

Hay, para ser precisos. un plano muy breve, en una pesadilla de Mandá, en el vemos a Dhavle durante la violación de Mandá. 


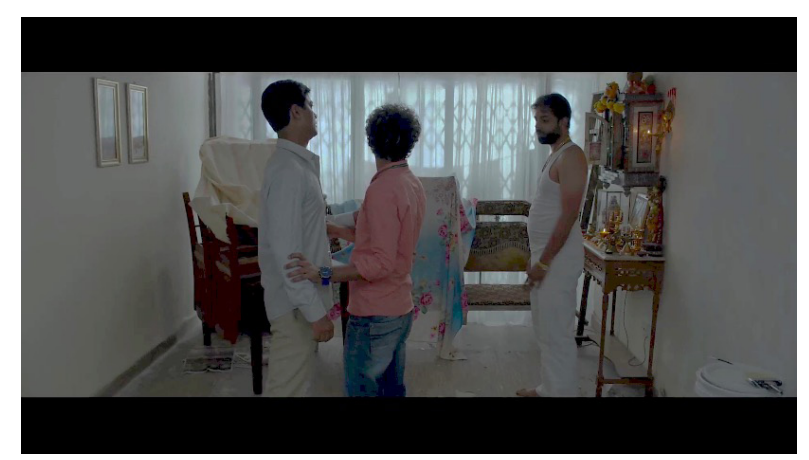

Imagen 1. Habitación de la casa de Dhavle con altar de Shiva.

[Fuente: Kumar y Mehra, 2017]

Resulta llamativo que, a excepción de Shiva, no se muestra ninguna otra imaginería religiosa, aunque las vestimentas -el sari- y las restricciones alimenticias -el vegetarianismo- inducen a pensar en que Ajji y su familia son hindúes - como mínimo, culturalmente- y que Sharafat es musulmán -tocado con kufi, carnívoro, y con clientela que viste de burka-. Otra opción de Destinador implícito podría ser el papel tradicional de las mujeres como cuidadoras de la familia en la cultura india, función que las principales mujeres del relato cumplen, pero la vertiente más violenta de esa función pensamos que, culturalmente, estaría más asociada a los varones, en ausencia de alusiones a deidades femeninas violentas, como sucede en otras películas. Otro posible Destinador implícito y simbólico podría ser la idea subyacente de justicia, de la necesidad de castigar la violación, así como que, ante el fracaso de la justicia ordinaria, sea válido acometer una acción justiciera.

Finalmente, cabría considerar las figuras paternas del relato como Destinadores simbólicos, El relato presenta dos padres: Milind, padre de Mandá; y Dhavle padre, padre del agresor. Sin embargo, no cumplen ninguna de las funciones del Destinador ni ejercen una función simbólica: Milind es una figura paterna débil, incapaz de luchar por que se haga justicia a su hija, y esta impotencia es subrayada por el grave corte que sufre en su mano derecha en un accidente en la fábrica textil en que trabaja, circunstancia esta que podría remitir a la amenaza de castración. Repárese, en la imagen dos, en la disminuida presencia de Milind en el plano en relación con las figuras de Ajji y de su esposa.

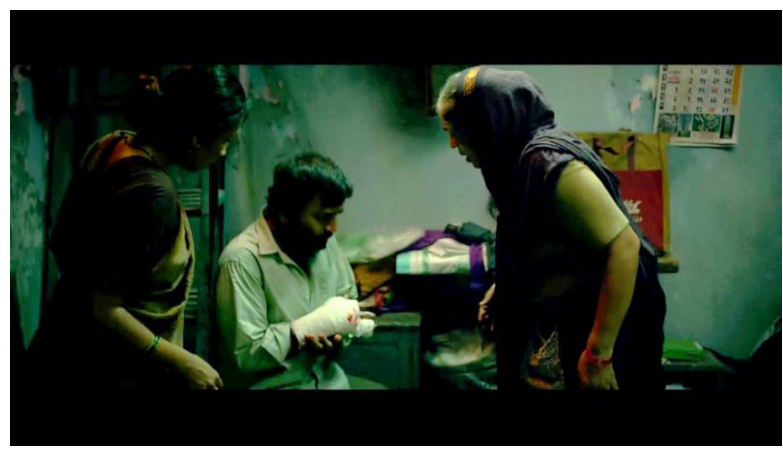

Imagen 1. Habitación de la casa de Dhavle con altar de Shiva. [Fuente: Kumar y Mehra, 2017] 
Por su parte, Dhavle padre podría asociarse a una figura paterna siniestra, ya que, aunque reprueba las fechorías de su hijo, probablemente por el riesgo que entrañan para su carrera, anula la acción de la ley contra ellas. En definitiva, no encontramos en Ajji un Destinador claro, evidente o simbólico; en todo caso, Destinadores parciales o implícitos, pero débiles o siniestros. Como resultado de ello, resulta difícil considerar Ajji un relato simbólico.

\subsection{La escena primaria}

En Ajji se observan dos agresores principales: un personaje masculino que agrede sexualmente a una niña; y un personaje femenino que emascula y mata a un varón. Ambos son presentados en algún momento con cierto carácter de fantasma: Dhavle, en un cartel de propaganda política de su padre al comienzo del relato, como se ve en la imagen tres; y Ajji, cuando se dispone a consumar la venganza, con el rostro completamente blanco para ocultar su edad, como muestra la imagen cuatro.

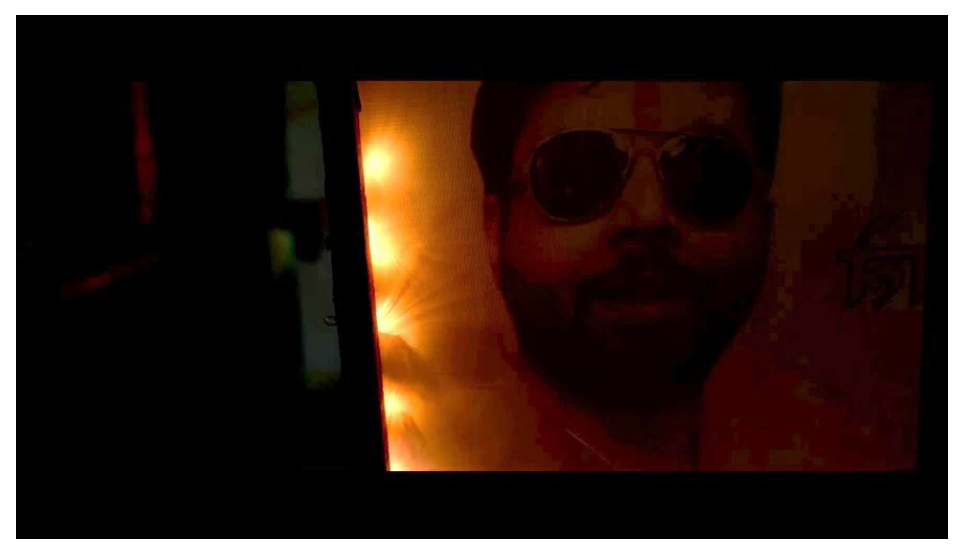

Imagen 3. Dhavle.

[Fuente: Kumar y Mehra, 2017]

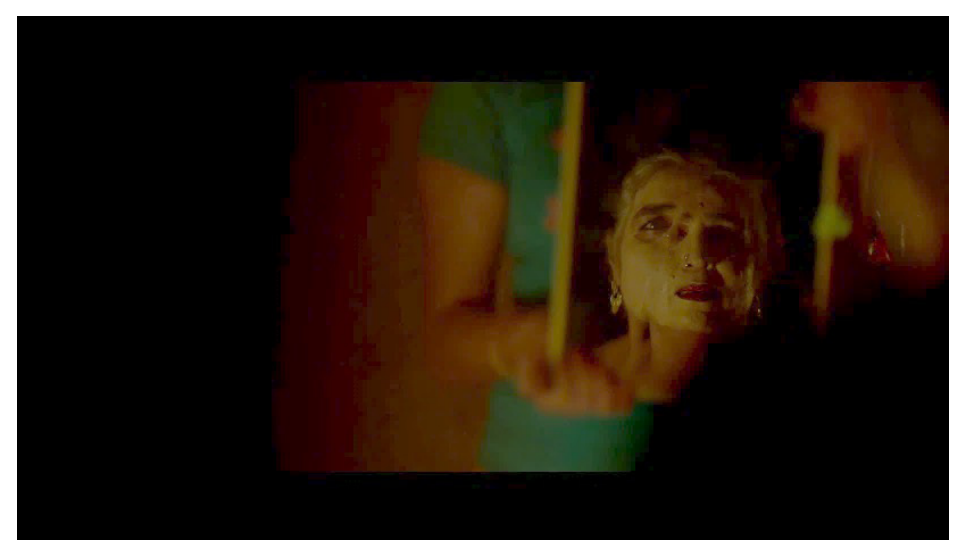

Imagen 4. Ajji.

[Fuente: Kumar y Mehra, 2017] 
No obstante, la potencia del agresor femenino es mayor, ya que resulta vencedor del enfrentamiento y consuma la amenaza de castración, uno de los elementos en juego en la escena primaria, ya que de ella depende desproveer o no a la figura materna de su omnipotencia. Apoya la hipótesis de una escena primaria con figura agresora materna ciertas vacilaciones en la identidad sexual, especialmente, en la escena de la violación del maniquí, en la que Umya, cómplice y alter ego de Dhavle, se traviste con una peluca femenina - como puede verse en la imagen cinco-; y Dhavle excita con la mano del maniquí los genitales de Umya, como muestra la Imagen 6.

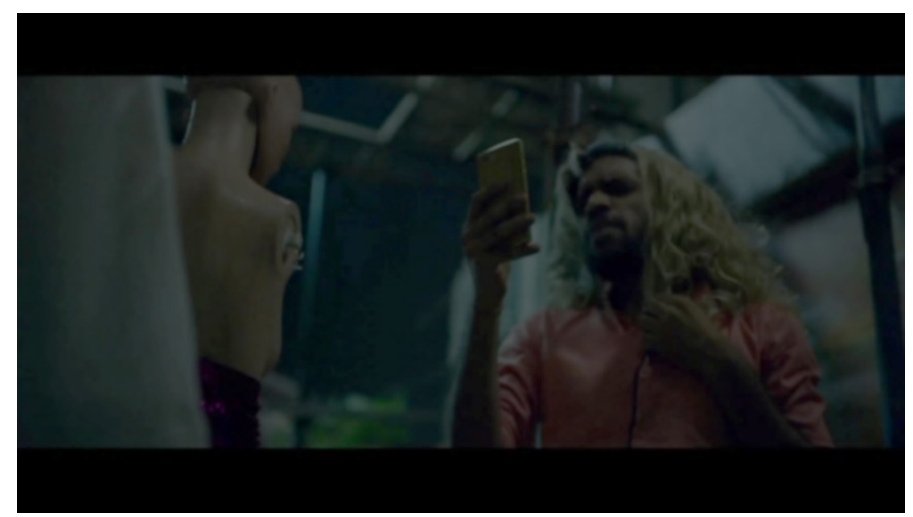

Imagen 5. Umya, travestido.

[Fuente: Kumar y Mehra, 2017]

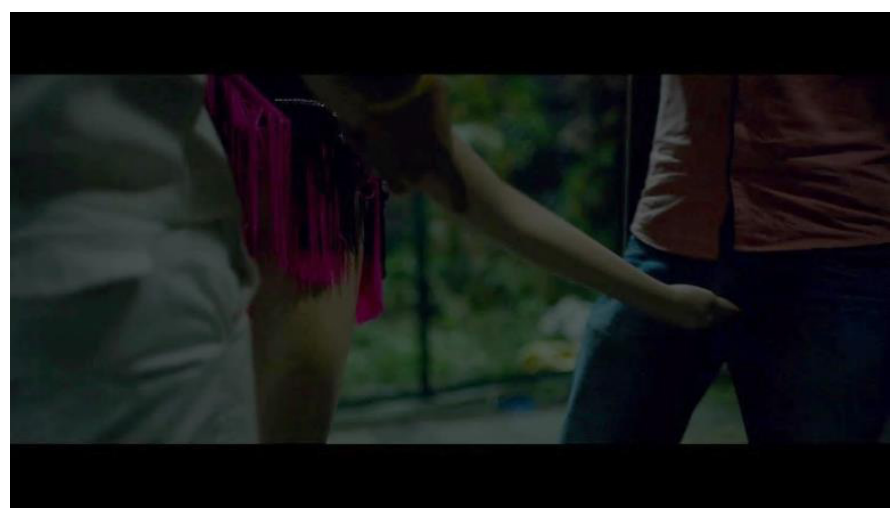

Imagen 6. Dhavle excita los genitales de Umya.

[Fuente: Kumar y Mehra, 2017]

Contribuye a la percepción de este tipo de escena primaria la ostentación por parte de la figura agresora femenina de un símbolo fálico, un cuchillo -como muestra la imagen siete- así como el reflejo recurrente de personajes femeninos (Vibha, Ajji, Mandá) en espejos, lo que remite a la fase del narcisismo primario, que González Requena denomina "la fase del espejo" (2006: 543), y en la que el niño se identifica, especularmente, con la figura materna primordial. Coherente con ello, cuando la figura paterna aparece en el espejo -ver la imagen ocho-, es empequeñecida en una esquina. Todo ello sugiere una escena primaria del tipo de "figura agresora materna". 


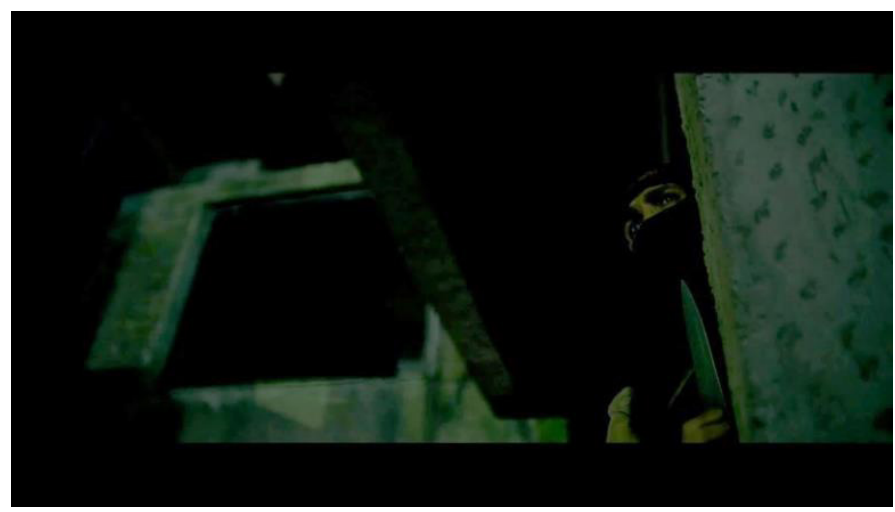

Imagen 7. La figura materna fálica.

[Fuente: Kumar y Mehra, 2017]

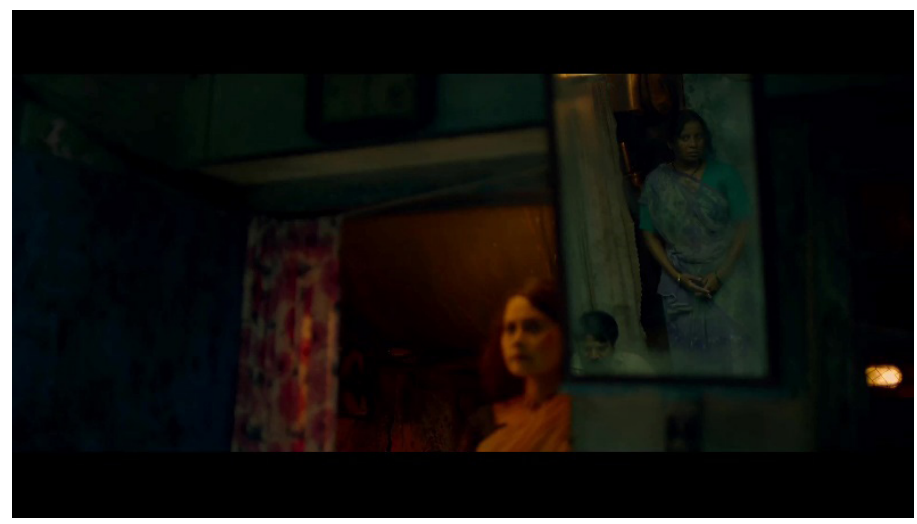

Imagen 8. Padre y madre, en el espejo.

[Fuente: Kumar y Mehra, 2017]

\subsection{Análisis de películas de violación y venganza indias coetáneas a Ajji}

Desde el punto de vista de la estructura de la trama, las películas seleccionadas siguen la estructura canónica de violación, fracaso de la ley y venganza. En Kaabil, los protagonistas son una pareja recién de casados ciegos. Ella es violada dos veces por el hermano de un político local y un amigo suyo. Tras la segunda vez, se suicida. La policía, corrompida por el hermano de uno de los violadores, no actúa contra ellos, y el marido de la víctima mata a ambos agresores. En Maatr, una adolescente y su madre son violadas por el hijo de un político local y sus amigos. La hija muere como resultado de la agresión. La madre identifica a sus agresores, pero no son condenados, y se venga de todos ellos. En Bhoomi, una joven es secuestrada y violada el día antes de su boda por un gángster local y sus amigos. Su novio cancela el casamiento cuando sabe de los hechos. La joven es violada de nuevo y dada por muerta. Los agresores no son condenados, y su padre y ella se vengan de ellos. En Mom, una adolescente es violada y dada por muerta por cuatro jóvenes. Los agresores son declarados inocentes en el juicio, y su madrastra se venga de los agresores. 
Violencia sobre las víctimas: en el conjunto de las cinco películas -incluyendo Ajji- hay seis víctimas de violación -en Maatr, se viola a dos ${ }^{6}$. Una de ellas -en Kaabil- es violada dos veces, por lo que hay siete violaciones. En Kaabil, la segunda violación conduce a su víctima al suicidio. De las seis víctimas de violación, dos de ellas -un 33,3\%-mueren: una por asesinato-Maatr-y, otra, por suicidio-Kaabil-.

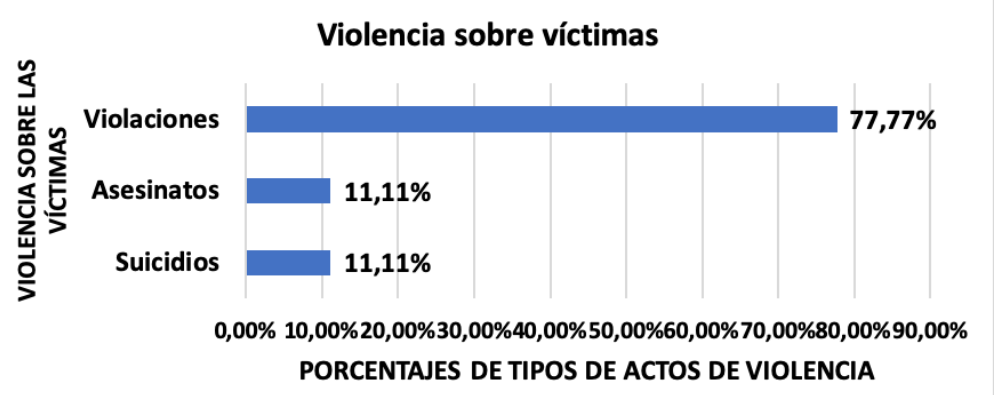

Tabla 1. Resultado de las agresiones sexuales en las películas de violación-venganza indias estrenadas en 2017. [Fuente: elaboración propia]

Violencia sobre los agresores: en cuanto a la violencia de la venganza, el número total de agresores es de diecisiete, repartidos del siguiente modo: dos en Kaabil, siete en Maatr; cuatro en Mom; tres en Bhoomi; y uno en Ajji. De los diecisiete, mueren quince (el 88,2\%): once son asesinados; dos se suicidan y dos mueren por accidente tratando de huir. Además, en Kaabil, un colaborador de los agresores también es asesinado por el vengador. De este modo, como resultado de la venganza, mueren dieciocho agresores o cómplices. Por otro lado, dos de los agresores son castrados -Mom y Ajji- y un tercero es obligado a autoemascularse - Bhoomi-. Dos de ellos mueren como resultado de la castración-Ajji y Bhoomi-. Por último, en una de las películas $-M o m-$, uno de los agresores termina en prisión. En la tabla dos, se compara la violencia de los agresores sexuales con la de los vengadores.

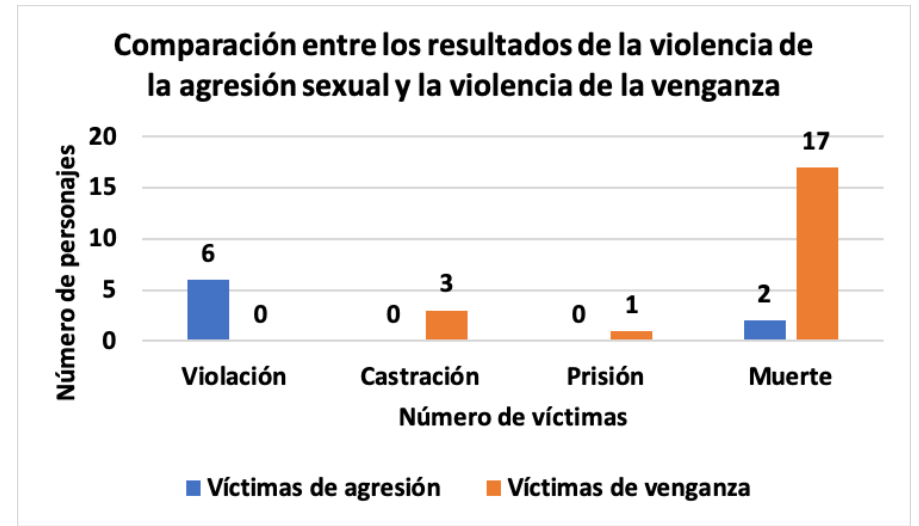

Tabla 2. Relación entre el resultado de la violencia de la agresión y el resultado de la violencia de la venganza. [Fuente: elaboración propia]

En Ajji, una segunda mujer es violada. Pero este cómputo hace referencia a las víctimas que desencadenan la venganza. 
Sexo de las víctimas: en las cinco películas, todas las víctimas de violación son mujeres.

Sexo de los agresores: todos los agresores son varones y, salvo en Ajji, aunque no queda del todo claro si el agresor actuó con su cómplice, siempre actúan en grupo: de dos en Kaabil; de tres en Bhoomi; de cuatro en Mom y de siete Maatr.

Sexo de los vengadores: en tres casos -Maatr, Mom y Ajji-, los vengadores son mujeres; hombre en el caso de Kaabi; y hombre y mujer -padre e hija-, en el caso de Bhoomi.

Edad de las víctimas ${ }^{7}$ : las edades de las víctimas de la violación abarcan desde una menor de diez años en Ajji; dos adolescentes en Maatr y Mom; dos jóvenes en la treintena en Bhoomi y Kaabil, y una mujer de unos cuarenta años en Maatr -ver tabla tres-.

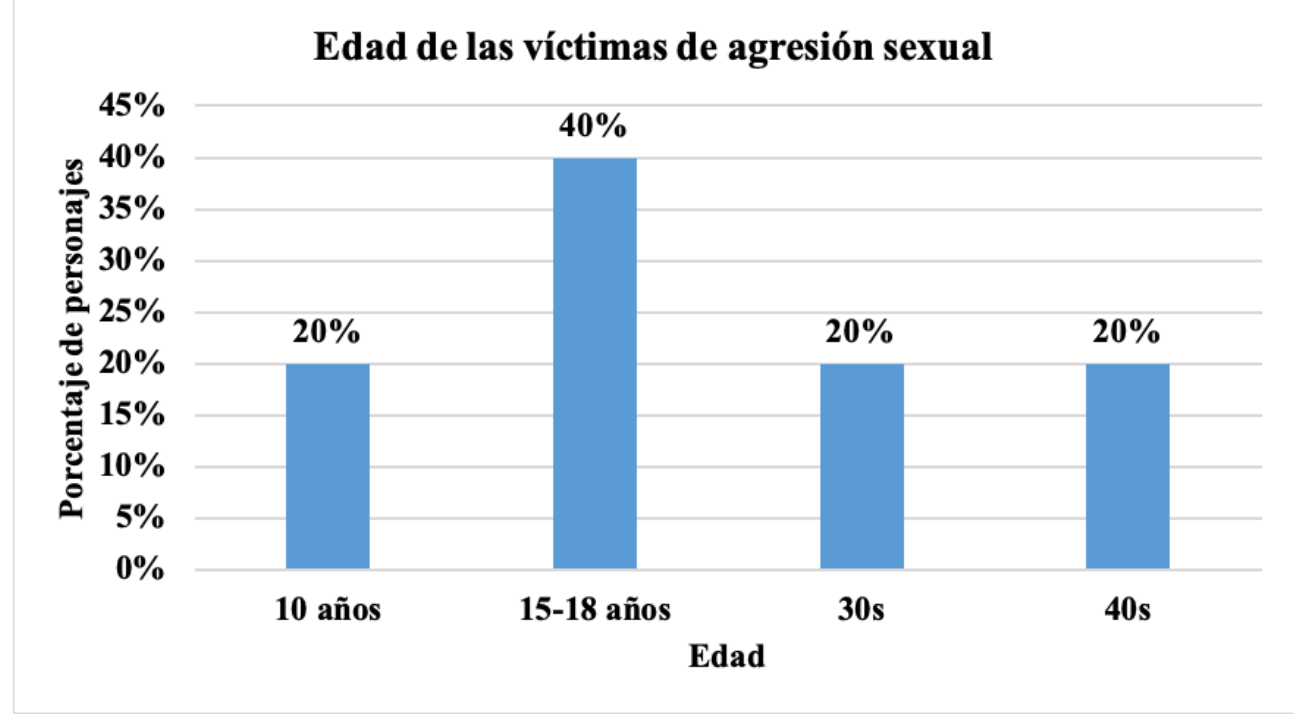

Tabla 3. Edad de las víctimas en las películas de violación-venganza indias estrenadas en 2017.

[Fuente: elaboración propia]

Edad de los agresores: la edad de los agresores oscila entre los veinte y los cuarenta años, aproximadamente.

Edad de los vengadores: en cuanto a la edad de los vengadores, mostrada en la tabla cuatro, encontramos dos en la treintena - Bhoomi y Kaabil-, uno en la cuarentena-Maatr-, dos en la cincuentena-Bhoomi y Mom-, y uno en los sesentena -Ajji-. 


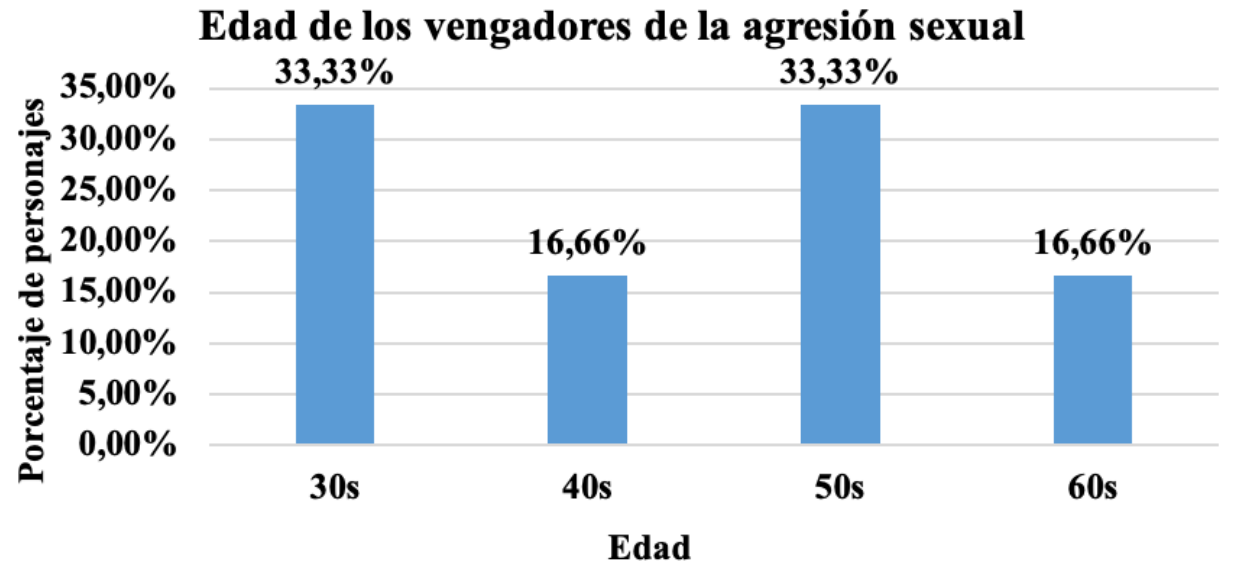

Tabla 4. Edad de los vengadores en las películas de violación-venganza indias estrenadas en 2017.

[Fuente: elaboración propia]

Relación de parentesco entre vengador y víctima: en una de las cinco películas el vengador es el padre de la víctima-Bhoomi-; en una es el marido-Kaabil-; en dos, la madre -Maatr y Mom-; en una es la abuela-Ajji-; y, en dos, la propia víctima es uno de los vengadores - Bhoomi y Mom-. Se observa, así, que la edad de las víctimas es semejante, en general, a la edad de los agresores, pero significativamente menor que la edad de los vengadores.

Tipo de Destinador: en ninguna de las películas un personaje encarna todas las funciones del Destinador, pero en todas ellas hay referencias a deidades hindúes que cumplen, en mayor o menor grado, estas funciones. Así, en Kaabil, los novios participan en la fiesta del dios Ganesha, una popular deidad protectora, según se ve en las imágenes nueve y diez.

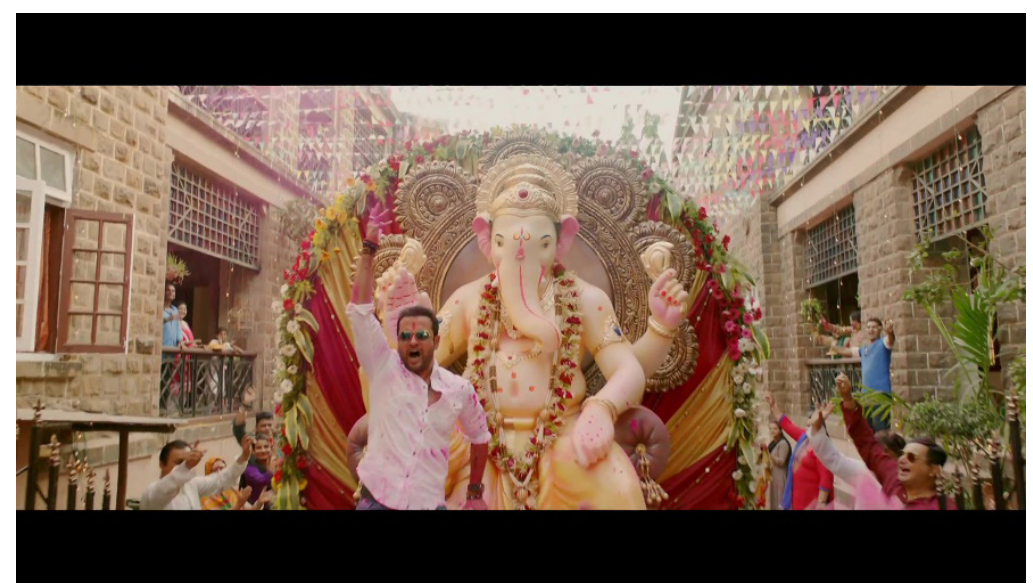

Imagen 9. Fiesta de Ganesha.

[Fuente: Roshan y Saini, 2017] 


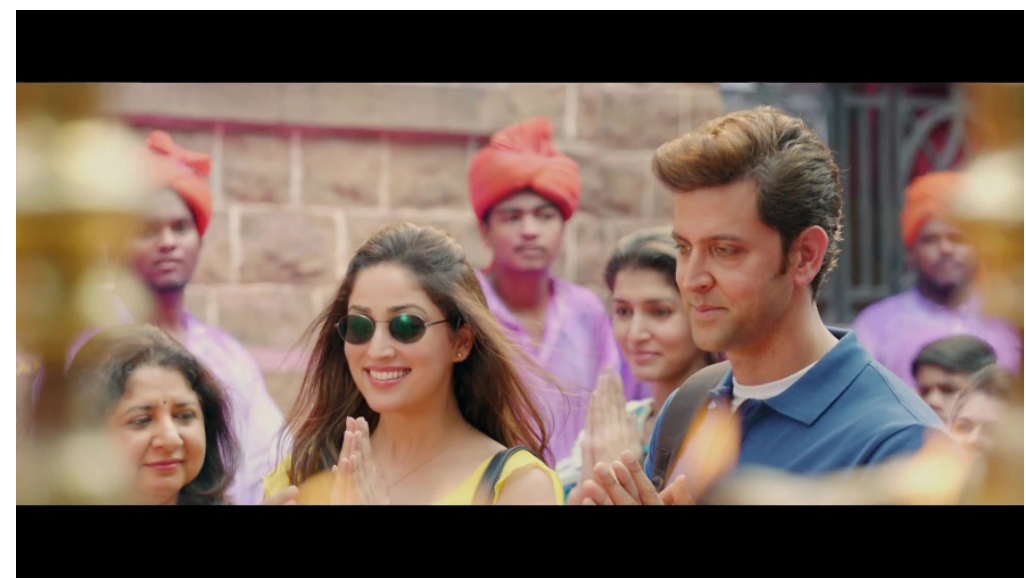

Imagen 10. Los protagonistas de Kaabil, en la fiesta de Ganesha.

[Fuente: Roshan y Saini, 2017]

En Maatr, en el inicio del relato, la víctima adolescente resume el Ramayana, en el que Rama libera a su mujer del demonio Ravana, La adolescente recuerda que "no es imposible derrotar a Ravana; uno solo necesita despertar a su dios Rama interior" (Maatr, 2017, 00:04:27- 00:06:36).

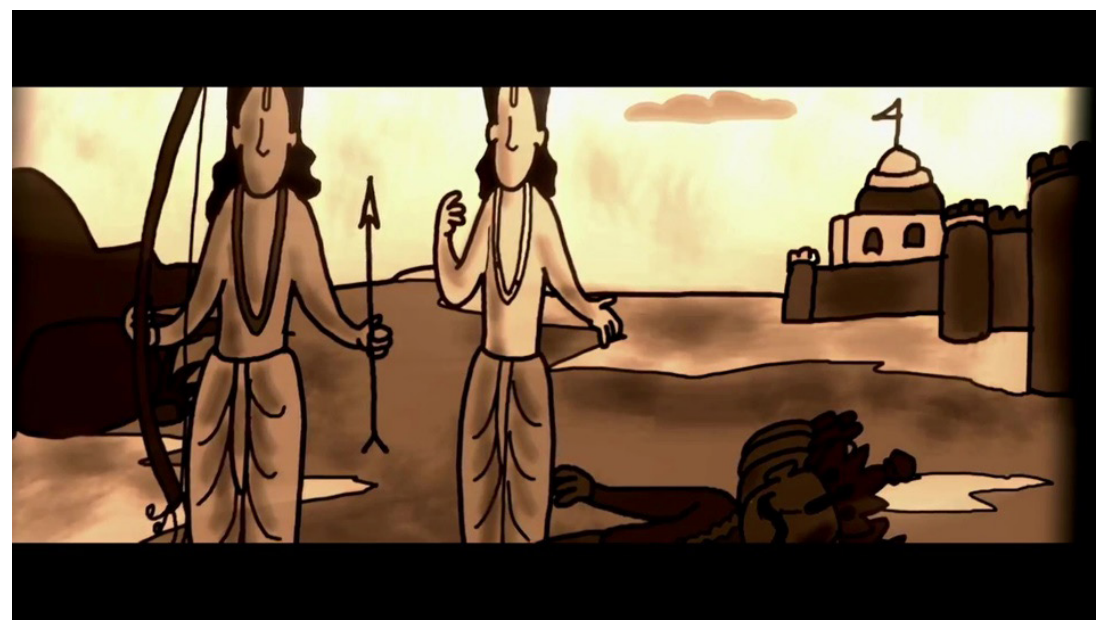

Imagen 11. Rama, tras matar a Ravana.

[Fuente: Adhikari, 2017]

Bhoomi es el nombre de la víctima de la película homónima, y el nombre de la diosa Tierra. Su padre es devoto del dios Ganesha, y la venganza final tiene lugar en un templo en que se adora a la diosa Durga. 


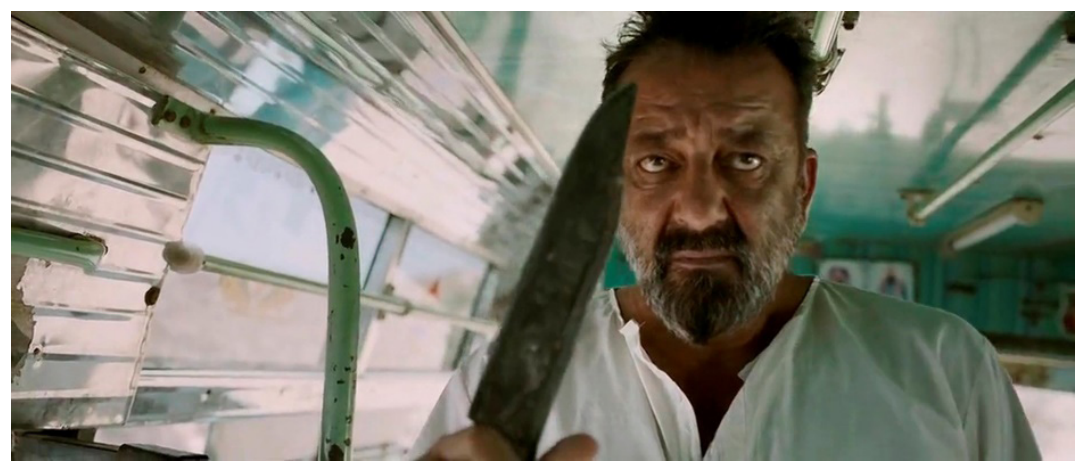

Imagen 12. La figura paterna fálica en Bhoomi.

[Fuente: Kumar, 2017]

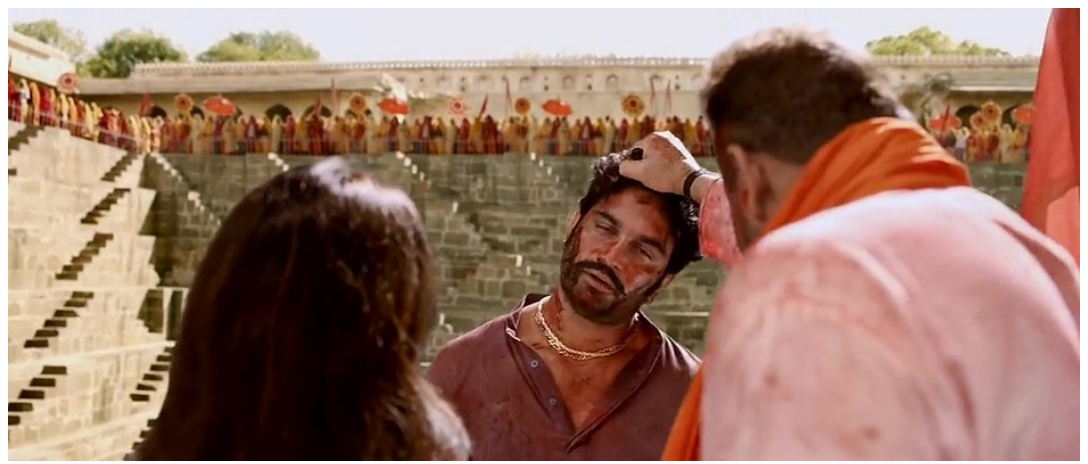

Imagen 13. Venganza final, en el templo dedicado a Durga.

[Fuente: Kumar, 2017]

En Mom, la protagonista toma la decisión de vengarse contemplando una obra de arte contemporáneo dedicada a Draupadi (ver Imagen 14).

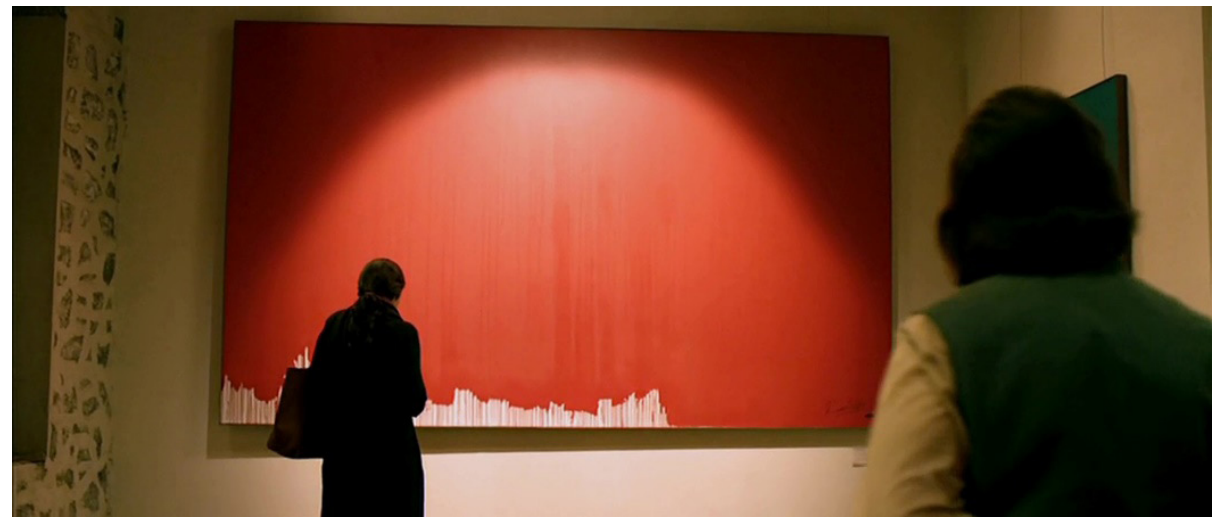

Imagen 14. La venganza de Draupadi.

[Fuente: Kapoor, 2017] 
Así, a excepción de Ajji, las películas de violación y venganza en hindi estrenadas en 2017 presentan un Destinador implícito que cabe denominarlo simbólico.

\subsection{Entrevistas al director de $A j j i$}

En sus declaraciones sobre Ajji, Devashish Makhija alude al inconsciente como fuente de los subtextos de su obra, que "emergen de la propia secuencia de experiencias, circunstancias e inspiraciones del propio artista. Estas, quizás, se han ido acumulando en su subconsciente durante toda su vida. Esta es la sima a la que desciende el artista para crear su obra" (Vasal, 2017). Makhija señala su inspiración en un relato simbólico, el cuento de hadas Caperucita roja (Kotzathanasis, 1019; Unbumf, 2017; Yoodle Films, 2017a), y refiere que exploró la posibilidad de que el personaje "más indefenso" e "improbable" del cuento ejerciera de justiciero (Kotzathanasis, 2019), del mismo modo en que asoció el personaje del lobo al agresor sexual (Yoodle Films, 2017b).

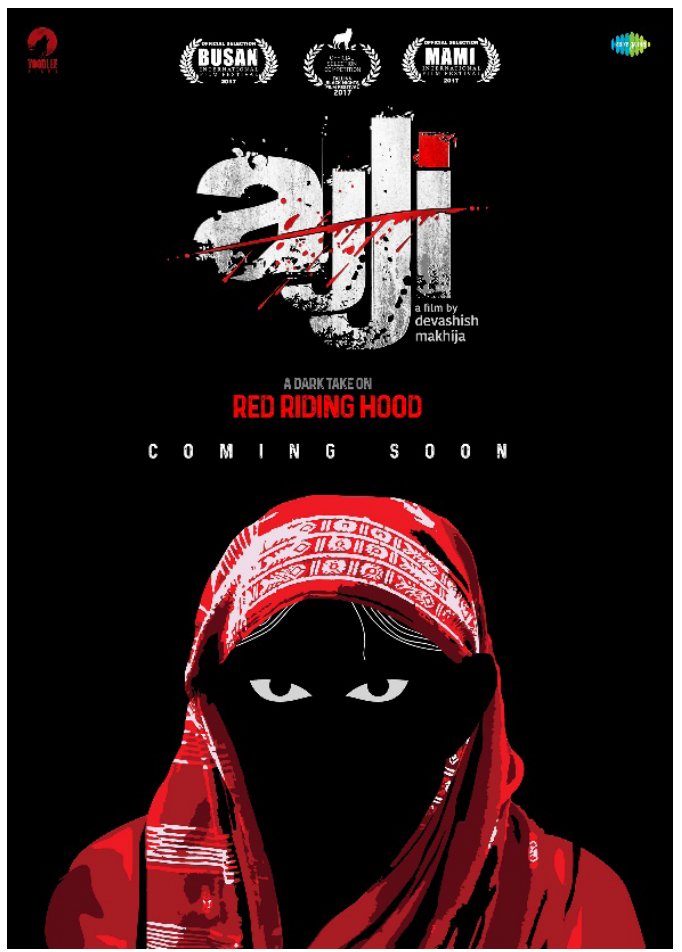

Imagen 15. Cartel de Ajji.

[Fuente: Kumar y Mehra, 2017]

En una entrevista personal realizada el diecisiete de mayo de 2019, Makhija explicó que se identifica con varios de los personajes: Milind, que siente "que ha fallado a todas las mujeres de su vida en un mundo misógino"; Leela, esclava de la prostitución pero que, si escapara de ella para casarse, estaría condenada a otro tipo de esclavitud; Vibha, porque, como ella, vivió varios años en Bombay "sin comida suficiente para poder sobrevivir"; Dastur, incapaz de defender la ley porque no so- 
meterse a Dhavle padre supondría la pérdida de su trabajo y ser discriminado para otros por su condición de musulmán en un sistema de mayoría hindú; y, en especial, con Ajji, porque "toda mi vida he mantenido mi ira bajo control gracias a poder reconducirla a las películas; pero, quita estas, y me convierto en Ajji" (Makhija 2019, comunicación personal, diecisiete de mayo). Asimismo, en la referida entrevista nos explicó que Ajji cumple su venganza con unas tijeras en lugar del cuchillo, porque, por su trabajo como modista, está más familiarizada con ellas, y ello aumentaba sus posibilidades de éxito. Por último, Makhija nos informó de que la deidad del altar de la casa de Dhavle es Shiva, dios de la reconstrucción de la vida, pero que puede ser utilizado para la destrucción. En un cortometraje previo, Taandav (Singh y Singh, 2016), exploró la energía de Shiva en sentido contrario a como lo hizo en Ajji.

\section{Discusión}

En el presente trabajo hemos estudiado la relación de la película india Ajji con el inconsciente, teniendo en cuenta películas del mismo género en su contexto espaciotemporal inmediato y las motivaciones personales del director. En relación con nuestro primer objetivo de estudio, en Ajji encontramos un relato con un eje de la Donación ausente o muy mermado, y sin un Destinador explícito que cumpla las cuatro funciones propias de esta figura narrativa. Pudieran considerarse Destinadores implícitos o parciales, pero no permiten considerar esta película un relato simbólico, lo que confirma la hipótesis. Ello es especialmente significativo si la comparamos con los cuatro filmes coetáneos estudiados, en los que se movilizan Destinadores simbólicos en forma de deidades hindúes. En este sentido, Ajji está más próxima al cine postclásico europeo, en el que el eje de la Donación está ausente, que al cine postclásico de Hollywood, con un marcado eje de la Donación pero un Destinador siniestro (Gonzáléz Requena, 2011).

Por otro lado, la ausencia de un Destinador simbólico es coherente con los rasgos de vacilación en la identidad sexual presentes en el filme, si aceptamos la relación de relato simbólico con una maduración canónica de la identidad sexual desde la perspectiva freudiana; e, igualmente, con la desolación que embarga a la protagonista una vez cumplido su deseo, ya que el acto justiciero, desde el punto de vista de lo narrativamente presente en el texto, carece del sentido del que lo hubiera dotado un eje de la Donación. Ello contrasta con la emoción de satisfacción por la justicia hecha a la que conducen desenlaces semejantes en las otras cuatro películas estudiadas.

En relación con otro de los objetivos de este trabajo, Ajji presenta una escena primaria con figura agresora materna que cumple la amenaza de castración. Lo que puede explicar el subtexto de Caperucita roja en el relato, ya que, desde una perspectiva de inspiración freudiana, se ha sugerido la articulación, en este cuento, del miedo a ser devorado por la madre y cómo superarlo (Bruno Bettelheim, 1975-1994). En cierto modo, este miedo a la voracidad materna puede ser entendido como el miedo a permanecer en la fase de narcisismo primario, en la que el individuo se identifica con una figura materna primordial. Aunque el autor de Ajji ha declarado su intención de caracterizar a Dhavle como el lobo del cuento, en el texto fílmico, es Ajji el personaje vinculado a un animal similar al lobo, el perro: dos perros le acompañan con sus aullidos cuando se dirige a la guarida de su víctima; y las dos castraciones que realiza, a una cabra muerta y a Dhavle, las concluye dando de comer los testículos 
a unos perros. Esto es acorde con la observación de González Requena de que el lobo de Caperucita roja es una figura materna, no solo por su embarazo siniestro de Caperucita y su abuelita, sino porque, de no serlo, “¿cómo le sería tan fácil -al lobodisfrazarse de la abuelita?" (2011: 352).

Finalmente, este estudio constata la asimetría entre la agresión sexual y la venganza referida por Gopalan (1997), siendo el resultado de venganza más violento que el de la agresión sexual, lo que podría remitir al componente sadomasoquista apuntado por algunos autores (Lehman, 1993; Clover 1993).

\section{Limitaciones}

Una limitación de este estudio es la derivada de un análisis de tipo fragmentario, sobre el que Santos Zunzunegui (1994) advierte que puede conducir a la no percepción del texto en su totalidad. Ello está relacionado con posibles sesgos de confirmación y ceguera por falta de atención, comunes a este tipo de investigaciones. Asimismo, el desconocimiento de experiencias vitales del director, especialmente en la infancia, que hayan podido condicionar deseos reprimidos, dificulta el análisis de la película desde el punto de vista utilizado. Por último, la distancia de la cultura del investigador respecto a la cultura en que se produce la película puede inducir una compresión deficitaria de aspectos de la misma.

\section{Conclusiones}

Este estudio constata la presencia del relato no simbólico y la escena primaria del tipo "figura agresora materna" en una película relevante de una industria cinematográfica cuyos relatos, habitualmente, están simbólicamente marcados por mitos religiosos (Dwyer, 2006). Si bien se trata de una obra de cine independiente, en el que el inconsciente del autor se manifiesta con mayor libertad que en el cine comercial, los premios y el éxito de crítica indican una repercusión no desdeñable y, por ello, los rasgos detectados pueden revelar una tendencia cultural más amplia hacia relatos no simbólicos. Si aceptamos que el análisis de los productos culturales, como el cine, puede contribuir a identificar corrientes psicológicas inconscientes que influyan en el devenir de la sociedad que los produce (Kracauer, 1947) y, en Occidente -"la primera civilización, a lo largo de toda la historia de la humanidad, absolutamente desprovista de mitos" (González Requena, 2006: 2)-, tanto la presencia masiva de relatos no simbólicos como la creciente presencia del tipo de escena primaria identificado en Ajji podrían estar contribuyendo a un creciente malestar, la constatación de este tipo de relatos en la cultura india podría apuntar a una extensión del fenómeno de desmitologización, cuyas consecuencias están aún por determinar. Futuras investigaciones podrían tratar de confirmar esta tendencia en otros textos mediante aproximaciones metodológicas mixtas, como la presente $y / o$ multidisciplinares. 


\section{Bibliografía}

Adhikari, M. (Productor) y Sayed, A. (Director). (2017). Maatr. India: Pugmark Films.

Bargh, J. A. y Morsella, E. (2008). "The Unconscious Mind". Perspectives on Psychological Science, vol. 3, núm. 1, 73-79. doi:10.1111/j.1745-6916.2008.00064.x

Barthes, R. (1977). "Introducción al análisis estructural de los relatos". En Silvia Niccolloni (comp.), El análisis estructural. Buenos Aires: Centro Editor de América Latina.

Bettelheim, B. (1994/ 1975). El psicoanálisis de los cuentos de hadas. Barcelona: Crítica.

Bhattacharya, A. (2019). "Why a 118-year-old Bollywood music label is now betting on offbeat films". Recuperado de https:/qz.com/india/1631997/after-t-series-saregama-indias-yoodlee-to-make-bollywood-films/ (Fecha de acceso: 03/05/2020).

Bollywoodmdb (2020). “Complete Bollywood Movies List 2017”. Recuperado de https:// www.bollywoodmdb.com/movies/bollywood-hindi-movies-list-of-2017-1 (Fecha de acceso: 04/05/2020).

Bordwell, D., Thompson, K. y Smith, J. (2017). Film Art: An Introduction. Nueva York: McGraw-Hill.

Bulkeley, K. (2003). "Dreaming and the Cinema of David Lynch". Dreaming, 13, 49-60 (2003). doi: 10.1023/A:1022190318612

Burguera, J. J. (2015). “Donación simbólica, donación siniestra: aportaciones sobre el cine de fantasía y el cine fantástico". Tesis Doctoral. Universidad Complutense de Madrid, Madrid.

Bogdanovich, P. (1998). This Is Orson Welles. Nueva York: Da Capo Press.

Casanova, B. (2011). "La enunciación en Ciudadano Kane”. Área Abierta, vol. 29, 1-15. doi: 10.5209/rev_ARAB.2011.n29.36199.

Chopra, A. (Productor) y Sarkar, P. (Director). (2014). Mardaani. India: Yash Raj Films.

Chopra, B. R. (Productor) y Chopra, B. R. (Director). (1980). Insaf Ka Tarazu. India: NH Studioz.

Clover, C. J. (1993). Men, Women, and Chain Saws. Princeton: Princeton University Press.

Cook, R. F. (2011). "Correspondences in visual imaging and spatial orientation in dreaming and film viewing". Dreaming, vol. 21, núm. 2, 89-104. doi: 10.1037/a0022866

Denzin, N. K. (1979). The Research Act. Nueva York: McGraw-Hill.

Dhingra, G. (Productor) y Nalin, P. (Director). (2015). Angry Indian Goddesses. India: Jungle Book Entertainment.

Dwyer, R. (2006). Filming the Gods. Oxon: Routledge.

Ebert, R. (1989) Movie Home Companion. New York: Andrews and McMeel.

Freud, S. (1900/1966). La interpretación de los sueños. Madrid: Alianza Editorial.

Freud, S. (1908/1976). "El creador literario y su fantaseo". En Sigmund Freud. Obras Completas, Tomo IX. Buenos Aires: Amorrortu, 123-136.

Freud, S. (1940). "Esquema de psicoanálisis". En Sigmund Freud. Obras Completas. Tomo XXII. Buenos Aires: Amorrortu, 135-209.

González Requena, J. (2006). Clásico, Manierista, Postclásico. Valladolid: Castilla Ediciones. González Requena, J. (2007). "El Análisis Fílmico desde la Teoría del Texto. A propósito de Goya en Burdeos, de Carlos Saura". En Javier Marzal Felici y Francisco Javier Gómez Tarín (ed.), Metodologías de análisis del film. Madrid: Edipo, 113-134.

González Requena, J. (2011). Escenas fantasmáticas. Un diálogo secreto entre Alfred Hitchcock y Luis Buñuel. Granada: Centro José Guerrero.

Gopalan, L. (1997). “Avenging women in Indian cinema”. Screen, vol. 38, núm., 42-59. doi: $10.1093 /$ screen/38.1.42 
Greenwald, A. G., McGhee, D. E. y Schwartz, J. L. K. (1998). "Measuring Individual Differences in Implicit Cognition: The Implicit Association Test". Journal of Personality and Social Psychology, vol. 74, núm. (6), 1464-1480 doi: 10.1037//0022-3514.74.6.1464

Greimas, A. J. y Courtés, J. (1982). Semiótica. Diccionario razonado de la teoría del lenguaje. Madrid: Gredos.

Heller-Nicholas, A. (2011). Rape-Revenge Films. A Critical Study. Londres: McFarland.

Internet Movie Data Base. (2017). “Ajji. Release Info". Recuperado de: https://www.imdb. com/title/tt6471054/releaseinfo?ref_=tt_dt_dt\#akas (Fecha de acceso: 06/05/2020).

Jha, A. M. (2017). "Rape-Revenge Films: A History of Violation". Recuperado de https:// www.openthemagazine.com/article/cinema/rape-revenge-films-a-history-of-violation (Fecha de acceso: 09/04/2020).

Kapoor, B. (Productor) y Udyawar, R. (Director). (2017). Mom. India: MAD Films.

Karki, I. (2018). "Scripting Resistance: Rape and the Avenging Woman in Hindi Cinema". Journal of International Women's Studies, vol. 20, núm. 4, 83-102.

Kotzathanasis, P. (2019). "Interview with Devashish Makhija: The anger I have felt on behalf of the wronged Adivasi (tribal), the unfairly treated minority, the subjugated lower class, the reviled worker class, I put all that into 'Ajji'". Recuperado de https://asianmoviepulse. com/2019/04/interview-with-devashish-makhija/ (Fecha de acceso: 09/10/2019).

Kracauer, S. (1947). From Caligari To Hitler. A Psychological History of the German Film. Princeton: Princeton University Press.

Kukunoor, N. (Productor) y Kukunoor, N. (Director). (2014). Lakshmi. India: Kukunoor Movies Production, SIC Productions y UV News Media \& Communication.

Kumar, O. (Productor) y Kumar, O. (Director). (2017). Bhoomi. India: T-Series.

Kumar, S. A. y Mehra, V. (Productor) y Makhija, D. (Director). (2017). Ajji. India: Yoodle.

Laplanche, J. y Pontalis, J.B. (1988). The Language of Psychoanalysis. London: Karnac.

Lehman, P. (1993). “'Don’t Blame This On A Girl””. En Steven Cohan e Ina Rae Hark (eds.) Screening The Male. Exploring masculinities in Hollywood cinema. Londres: Routledge, 103-117.

Levy, E. (1999). Cinema of Outsiders: The Rise of American Independent Film. Nueva York: New York University Press.

Marcus, L. (2008). "Dreaming and Cinematographic Consciousness". Psychoanalysis and History, vol. 3, núm. 1, 51-68. doi: 10.3366/pah.2001.3.1.51

McKee, R. (2009). El guión. Barcelona: Alba Editorial.

Merikle, P. M. y Joordens, S. (1997). "Parallels between perception without attention and perception without awareness". Consciousness \& Cognition, vol. 6, 219-236. doi: 10.1006/ ccog. 1997.0310

Mulvey, L. (1989) “Afterthoughts on 'Visual Pleasure and Narrative Cinema' inspired by King Vidor's Duel in the Sun (1946)". En: Visual and Other Pleasures. Language, Discourse, Society. Londres: Palgrave Macmillan, 29-28.

Propp, V. (1928/1971). Morfología del cuento. Madrid: Fundamentos.

Punjabi, A. (Productor) y Bhogal, A. (Director). (1988). Zakmi Aurat. India: Manta Movies.

Rao, R. (Productor) y Krishna. T. (Director). (1985). Pratigath. India: Usha Kiron.

Read, J. (2000). The New Avengers. Feminism, feminity and the rape-revenge cycle. Manchester: Manchester University Press.

Roshan, R. y Saini, S.(Productor) y Sanjay, G. (Director). (2017). Kaabil. India: Film Kraft. Tate, J. (1988). The Magic Lantern: An Autobiography. Londres: Hamish Hamilton.

Singh, A. y Singh, P. (Productor) y Makhija, D. (Director). (2016). Taandav. India: Indie Muviz PTE. 
Teddlie, C. y Tashakkori, A. (2009). Foundations of Mixed Methods Research. Los Angeles: SAGE.

The West End Magazine | 4101-TV. (2015). "David Lynch - Between Two Worlds - Press Conference". Recuperado de https:/www.youtube.com/watch?v=OwGqi4YT6XY (Fecha de acceso: 30/04/2020).

UnBumf. (2017). “An Interview with Devashish Makhija”. Recuperado de https://youtu.be/ WPB3WmLTJIw (Fecha de acceso: 16/09/2019).

Vasal, N. (2017). “An Interview With Devashish Makhija: The Filmmaker Who Is Breaking The Stereotypes”. Recuperado de https://unbumf.com/devashish-makhija-interview/ (Fecha de acceso: 06/08/2019).

Virdi, J. (1999). "Reverence, rape - and the revenge: popular Hindi cinema's woman's film". Screen, vol. 40, núm. 1, 17-37. doi: 10.1093/screen/40.1.17

Virdi, J. (2003). The Cinematic ImagiNation. New Brunswick: Rutgers University Press.

Williams, L. (1983). "When the Woman Looks.” En Mary Ann Doane, Patricia Mellencamp, y Linda Williams (ed.) He-Vision: Essays in Feminist Film Criticism. American Film Institute Monograph Series, vol. 3, 83- 99. Frederick, Md.: University Publications of America.

Wilson, E. P. (2018). “'Room, door. . room': Oneiric space in L'Avventura and Last Year in Marienbad”. Dreaming, vol. 28, núm. 2, 162-168. doi: 10.1037/drm0000075

Yoodle Films (2017a). “Official Page of Ajji”. Recuperado de https://www.saregama.com/ yoodleefilms/ajji.html (Fecha de acceso: 05/05/2020).

Yoodle Films. (2017b). "Ajji |The Cinematic Language - Behind The Scenes | Selected in Busan \& MAMI Film Festivals”. Recupèrado de https://youtu.be/iQNmZoBJhdY (Fecha de acceso: 02/09/2019).

Zunzunegui, S. (1994). Paisajes de la forma: ejercicios de análisis de la imagen. Madrid: Cátedra. 